\title{
Mild cognitive impairment history and current procedures in low- and middle-income countries a brief review
}

\author{
Larissa Hartle ${ }^{1,2}$, Helenice Charchat-Fichman ${ }^{1 \odot}$
}

\begin{abstract}
Mild cognitive impairment (MCI) is a widely studied concept that has changed over time. Epidemiology, diagnosis, costs, prognostics, screening procedures, and categorization have been extensively discussed. However, unified guidelines are still not available, especially considering differences between low- and middle-income countries (LMIC) and high-income countries (HIC). Objectives: To contextualize and identify the main areas under investigation regarding $\mathrm{MCl}$ diagnosis and to investigate how much of the current knowledge is compatible with the diagnosis in an LMIC. Methods: This brief review followed the framework outlined for a scoping review and goes through the history of $\mathrm{MCl}$ and its diagnosis, the differences and relevance of LMIC research regarding the concept, and the current criteria for diagnosis. Results: Results show that the unique characteristics of LMIC influence the development of cognitive decline and how suitable procedures suggested by HIC can be used by LMIC to identify pathological aging processes in their early stages. Conclusion: Neuropsychological assessment of activities of daily living performance, considering the difference between omission and commission errors, is a more accessible course of action as a screening procedure for cognitive decline in LMIC.
\end{abstract}

Keywords: mild cognitive impairment, aging, activities of daily living, cognition disorders.

\section{HISTÓRIA E PROCEDIMENTOS ATUAIS EM PAÍSES DE BAIXA E MÉDIA RENDA PARA 0 COMPROMETIMENTO COGNITIVO LEVE: UMA BREVE REVISÃO}

RESUMO. 0 comprometimento cognitivo leve (CCL) é um conceito amplamente estudado que mudou ao longo do tempo. Epidemiologia, diagnóstico, custos, prognósticos, procedimentos de triagem e categorização já foram amplamente debatidos. No entanto, diretrizes unificadas ainda não estão disponíveis, especialmente considerando as diferenças entre países de baixa e média renda (PBMR) e países de alta renda (PAR). Objetivos: Contextualizar e identificar as principais áreas de pesquisa em relação ao diagnóstico do CCL e investigar quanto do atual conhecimento é compatível com o diagnóstico em PBMR. Métodos: Esta revisão se guiou a estrutura delineada para uma scoping review, percorrendo a história do CCL, o diagnóstico, as diferenças e a relevância da pesquisa de PBMR para o conceito e os critérios atuais para diagnóstico. Resultados: Os resultados mostram que as características únicas dos PMBR influenciam o declínio cognitivo e como os procedimentos sugeridos por PAR podem ser usados por PBMR para identificar processos de envelhecimento patológico em seus estágios iniciais. Conclusão: A avaliação neuropsicológica de atividades de desempenho de vida diária, considerando a diferença entre erros de omissão e comissão, é um curso de ação mais acessível como um procedimento de triagem para declínio cognitivo em PMBR.

Palavras-chave: comprometimento cognitivo leve, envelhecimento, atividades cotidianas, distúrbios cognitivos.

\section{INTRODUCTION}

The latest United Nations World Popula-

1 tion Aging Reports ${ }^{1,2}$ raised important issues about global aging. The global population aged 60 or older more than doubled from 1980 to today. The expectation is that it will double again by 2050, reaching over two billion and surpassing the number of children and teenagers aged between 10 and 24 . According to the 2017 report, life expectancy has increased more than twenty years

\footnotetext{
This study was conducted during Larissa's master's studies under a double degree agreement between Pontifícia Universidade Católica do Rio de Janeiro and Università degli Studi di Perugia.

'Department of Psychology, Pontifícia Universidade Católica do Rio de Janeiro, Rio de Janeiro, RJ, Brazil. ²Department of Philosophy, Social, Human and Education Sciences, Università degli Studi di Perugia, Perugia, Italy.

Larissa Hartle. Piazza G. Ermini, 1 - 06123 - Perugia, Italy. E-mail: larissahartle@gmail.com

Disclosure: The authors report no conflicts of interest.

Funding: Larissa Hartle acknowledges funding from the Coordination for the Improvement of Higher Education Personnel (CAPES)

Received on November 19, 2020. Accepted in final form on February 07, 2021.
} 
globally since 1950 - reaching more than 70 years old. By 2050, the report estimates that global life expectancy will exceed 80 years old in Europe, Latin America, and Oceania. In Africa and Asia, it is expected to surpass 70 years old. The numbers are growing faster in developing countries, where $80 \%$ of older adults are expected to be living by 2050 .

Different pathological conditions are related to aging. The cognitive decline caused by neurodegenerative disorders is one of them. ${ }^{3}$ Such disorders cause extensive disability in the long term, and no or few treatments are available. For this reason, these disorders, grouped under the term dementia, today are a considerable economic and public health challenge. ${ }^{3}$ Worldwide, the global costs of dementia are increasing and went from US $\$ 604$ billion in 2010 to US $\$ 818$ billion in $2015 .{ }^{4}$ In 2017, the mean value of care was estimated to be US\$ 321,780 per person with dementia, more than two times the health expenses of older adults without the condition. ${ }^{5}$

If some decades ago it was enough, regarding neurodegenerative disorders, to differentiate between normal aging and dementia, today early detection is the goal to enable early interventions. ${ }^{6}$ In this context, mild cognitive impairment (MCI) increases as a relevant concept. $\mathrm{MCI}$ is seen as a preclinical stage of dementia. ${ }^{7}$ Although there are other prognostics, ${ }^{8}$ people diagnosed with $\mathrm{MCI}$ have a higher rate of dementia development than those not diagnosed. ${ }^{9}$ Of diagnosed dementia cases, $75 \%$ are Alzheimer's disease (AD). ${ }^{7}$ Population studies that indicate the prevalence of $\mathrm{MCI}$ in the population vary significantly in their results due to different diagnostic criteria, differences between prospective and retrospective analyses, and according to which MCI subtypes are being sought. ${ }^{10}$ The estimate of older adults with $\mathrm{MCI}$ ranges from 12 to $18 \%$ globally, ${ }^{6}$ although some studies reach percentages as high as $42 \%$ in particular countries. ${ }^{11}$

There are fewer data available in low- and middle-income countries (LMIC), although dementia increase is more prominent in those places. ${ }^{7,12}$ In Latin American countries (LAC), the reported prevalence of dementia varies between 2 and 13.7\%. ${ }^{12}$ Usually, there are more MCI cases than dementia, ${ }^{11}$ so a number higher than this should be expected. In Brazil, one study reported an incidence rate per 1000 person-years for MCI of 13.2, whereas globally the same incidence is usually between 8.5 and $31.9 \% .{ }^{13}$ Direct and indirect costs of dementia in Brazil are estimated to be more than US\$16,000 per patient annually, ${ }^{14}$ so any percentage becomes a challenge not only to individuals and their families but also to society.
Even so, most of the current discussion about MCI comes from the landscape in high-income countries (HIC). ${ }^{12}$ Thus, it is imperative to (1) contextualize and identify the main areas under investigation regarding $\mathrm{MCI}$ diagnosis and (2) investigate how much of the current knowledge is compatible with the diagnosis in an LMIC context, which were the aims of this brief review.

\section{METHODS}

This brief review followed the framework outlined for a scoping review proposed by Arskey and O'Malley ${ }^{15}$ with some modifications regarding the analysis of the results. It can be divided into two parts. First, with the object of mapping the main areas where research about MCI is being done, an initial literature search was conducted. The terms (mild cognitive impairment) AND diagnosis AND ((cognition) OR (neuropsychological assessment) OR (functionality) OR (activities of daily living)) were used in PubMed to retrieve data from two resources from the last five years: MEDLINE and PubMed Central. Given the overwhelming number of results, they were briefly analyzed until new results were considered superfluous to define the areas of interest useful to address the main research question. This first search defined this review article's initial structure, i.e., Historic, Diagnosis, Cognition performance, and Activities of daily living sections.

After the first search, a second search with the same keywords was conducted regarding the Scielo database to retrieve data on LMIC. Results were analyzed in the same way, but this time regarding their fit to the sections already defined. As advised by Arksey and O'Malley, ${ }^{15}$ we also checked the bibliography of all studies included and hand-searched key journals. After identifying the relevance of each topic to address LMIC's context influencing diagnosis, the Cognition section was merged with the Diagnosis section, and the Activities of daily living section was divided into Activities of daily living assessment, Activities of daily living performance awareness, and Types of errors in activities of daily living performance.

\section{HISTORIC}

The term MCI was used for the first time by Reisberg et al. in $1982 .{ }^{16}$ It referred to the third stage on a scale of seven stages regarding $\mathrm{AD}$ progression. At that time, it was characterized mainly by a decline in memory capacity. The scale, named the Global Deterioration Scale, goes from a typical aging profile to severe dementia, where all basic activities of daily living (ADL) and verbal and psychomotor behaviors are compromised. ${ }^{16}$ In the 
same year, other authors also named mild dementia as the third of five stages of Alzheimer's progression. ${ }^{17}$ This scale was called the Clinical Dementia Rating (CDR). Morris ${ }^{18}$ described the same condition ten years later. This scale resembles the current $\mathrm{MCI}$ concept but is not identical to it. ${ }^{10}$

It was Petersen who in 1999 refined the concept and started its current use. ${ }^{6,10}$ Regarding this definition, $\mathrm{MCI}$ was first described as the initial stage of $\mathrm{AD}$. It was characterized predominantly by a decline in memory more than that expected for a specific age but not yet sufficient for the diagnosis of dementia. ${ }^{19}$ In 2004, the diagnostic entity of MCI was expanded. It went from being a stage of $\mathrm{AD}$ marked by memory decline to (1) embrace other cognitive domains and (2) be associated with other etiologies besides AD. Some examples are cognitive impairment related to vascular disease, frontotemporal and Lewy body dementia, and sleep and mood disorders. ${ }^{6}$ On the basis of this new definition, MCI was divided into four subtypes: (1) amnestic single-domain; (2) amnestic multiple-domain - when there is memory decline concomitantly with decline in other functions; (3) non-amnestic single-domain; and (4) non-amnestic multiple-domain - when there is no memory decline, but there are one or more compromised functions other than memory. ${ }^{6}$

But studies using different criteria lead to distinct classifications..$^{20}$ Other categories have been proposed mostly because there is no clear and specific guideline to identify MCI. ${ }^{21}$ Criteria have been modified over time and have not yet reached a consensus. ${ }^{8}$ Nevertheless, the American Academy of Neurology concluded from an evidence-based medical review that the construct of $\mathrm{MCI}$ is of great clinical utility given the higher rate of conversion of diagnosed individuals to dementia compared to undiagnosed individuals. ${ }^{22}$ Besides that, the Diagnostic and Statistical Manual of Mental Disorders also incorporated similar concepts. The fourth version of the "Diagnostic and Statistical Manual of Mental Disorders (DSM-IV)" mentioned Age-Related Cognitive Decline in the section "Other Conditions That May Be a Focus of Clinical Attention". On the other hand, DSM-V incorporated Mild Neurocognitive Disorder in the neurocognitive disorders chapter, with diagnostic criteria similar to MCI. ${ }^{6}$

\section{DIAGNOSIS}

Although there are no unified guidelines to diagnose $\mathrm{MCI}$, today neuropsychological assessment is seen as a useful tool to detect the condition. ${ }^{8}$ Different options have similar diagnostic accuracy, ${ }^{23}$ but brief options seem to primarily identify only the amnestic subtype, whereas other types would need a more comprehensive battery. ${ }^{24}$ Studies using the Mini-Mental State Examination (MMSE) as a gold standard show MoCA as the best tool to screen for $\mathrm{MCI},{ }^{25}$ although there are recommendations not to use MMSE as a measure for comparison. ${ }^{23}$ In Argentina, MoCA was found to have good accuracy in identifying both $\mathrm{MCI}$ and dementia, but it is influenced by educational level. ${ }^{26}$ In fact, more comprehensive analyses show MoCA as more suitable for screening for dementia than for MCI. ${ }^{27,28}$ In Brazil, one study also found that MoCA is the most recommended tool to screen for dementia, but it is not so accurate when screening for cognitive decline before a dementia diagnosis or for low educational levels. ${ }^{29}$

In these scenarios, characterized by a population with a more diverse culture and education background, other options seem to have advantages but are better for detecting dementia than MCI. ${ }^{25,30}$ Analyses comparing medical diagnosis to the assessment of processing speed measures reached similar results. ${ }^{31}$ Therefore, there is still room for discussion on how to detect MCI, especially considering its heterogeneity and considering the different contexts seen in LMIC and HIC.

For example, another way of diagnosing $\mathrm{MCI}$ in HIC is the use of biomarkers. HIC have been using biomarkers in research and clinical settings, but the approach seems to be restricted to those countries and some upper-middle-income countries. ${ }^{12}$ Biomarkers are measurable biological indicators of a physical condition. ${ }^{7}$ Examples are analysis of tau and phospo-tau protein, cerebrospinal fluid, beta-amyloid, fibrillar $\mathrm{AB}$ burden, and brain imaging. ${ }^{8,21}$ Current studies indicate that tau protein levels and beta-amyloid in the brain can be handy not only to detect MCI, but also to define its etiology. ${ }^{6}$ Biomarkers can also help determine the likelihood of progression from $\mathrm{MCI}$ to $\mathrm{AD}^{8}$ and even detect cognitive alterations before $\mathrm{MCI}$ occurs. ${ }^{21}$ Although this would make a preclinical diagnosis possible, the biomarkers' clinical utility and benefits have also been questioned. ${ }^{12,21}$ The method is accurate and valued in research settings, but the cost is high, ${ }^{21}$ and most LMIC do not have access to the equipment needed. ${ }^{12}$

Due to all these disadvantages and difficulties, neuropsychological assessment is still a more reasonable approach to detect MCI, especially in LMIC. ${ }^{12}$ Considering the original criteria proposed by Petersen, ${ }^{6}$ the diagnosis is made on the basis of a cognitive decline complaint verified by clinical analyses, such as neuropsychological assessment. It must be determined whether there are one or more cognition areas affected, and the neuropsychological assessment is extremely useful to 
do so. ${ }^{32}$ According to the original criteria, ADL should also be analyzed. They should be preserved in MCI to make a differential diagnosis between this condition and dementia.

Although these conventional criteria exist, there is no unified approach to $\mathrm{MCI}$ diagnosis, ${ }^{8}$ and different cutoff points are used to define when a cognitive domain is impaired..$^{33}$ Besides that, these criteria cover a broad spectrum of heterogeneous profiles and can present themselves as the initial stage of different dementias and affect other cognitive domains. Individuals with amnestic MCI single domain, for example, have an increased risk for developing AD. On the other hand, attention, concentration, and visuospatial deficits may indicate Lewy body dementia. Behavioral changes, inappropriate behavior, and executive problems can indicate a dysexecutive $\mathrm{MCI}$ and possible frontotemporal dementia. ${ }^{6}$ There is, however, also a possibility of staying stable or improving after an $\mathrm{MCI}$ diagnosis. ${ }^{34}$ Moreover, data from autopsy and imaging studies reveal that mixed pathologies are common. ${ }^{8}$

Moreover, there are still other factors that can affect $\mathrm{MCI}$ categorization, and education is one of them. ${ }^{21}$ This is crucial when thinking about how $\mathrm{MCI}$ and dementia affect LMIC, where access to education is not the same as in HIC. A Brazilian study found a $12.7 \%$ higher rate of MCI among illiterates. An analysis of Brazilian older adults without dementia showed that education was the best predictor of MMSE total score. ${ }^{35}$ This means years of education impact neuropsychological assessment results and, therefore, detection of cognitive decline. The results of other studies show that educational levels influence performance in the majority of analyzed tests regarding different cognitive domains ${ }^{36}$ and are also linked to functional disability and frailty. ${ }^{37}$ Some tests are not even designed to evaluate this population. ${ }^{38}$ The executive functioning performance also seems to be linked to educational level, as a community sample of Rio de Janeiro showed. ${ }^{39}$

One possible explanation is the influence of educational level in the formation of cognitive reserve. Cognitive reserve, formed by exposure to educational level and complex activities throughout life, would help resist neural damage. ${ }^{40}$ Because the educational level is usually higher in HIC, people would be more protected from cognitive decline than people of the same age in LMIC. In fact, findings show that successful aging predictors may be different between developing countries, such as Brazil, and HIC. In the former, socioeconomic status and social network structure may prevail over biological determinants, ${ }^{41}$ although a sixteen-year follow-up study showed that age and sex were the best predictors. ${ }^{42}$
Therefore, besides not being able to use the same methods in research and clinical settings as HIC, such as the use of biomarkers, LMIC older adults may also be exposed to unique adverse conditions during life, leading to different patterns in aging. An epidemiological study in São Paulo, Brazil and Buenos Aires, Argentina found higher rates of dementia in slums compared to developed countries. ${ }^{7}$ With all the difficulties presented in the screening for MCI, especially in LMIC, there is still one consensus: it is essential to diagnose pathological aging in its early stages when treatments work best. ${ }^{43}$ To do so, as seen, there is a need for screening tools in primary care that are fast and easy to administer and have high sensitivity and specificity for different backgrounds. ${ }^{25}$ It is still necessary to investigate the topic and search for ways to screen for $\mathrm{MCI}$ as a routine procedure during aging, especially in LMIC.

Ideally, this screening would be able to detect MCI in all its heterogeneity. While the cognitive criteria can be differently affected throughout all MCI types, the other MCI diagnosis criterion, functionality, might be more evenly affected. There is actually some controversy if ADL are intact or already impaired at the beginning of cognitive decline. A meta-analysis suggested the possibility of a continuum in the development of functional impairment, which would already begin to occur at $\mathrm{MCI}{ }^{44}$

But besides the discussion about whether there are already functional impairments in MCI, it is also important to address if individuals are aware of eventual impairments. If not, this would not be a complaint, so it could not be screened by self-report scales or be a variable for intervention planning. One example of functional deficit detection utility is an estimation that predicted a $10 \%$ reduction in life cost of individuals with dementia with an early intervention addressing functionality difficulties during one year. ${ }^{5}$ Assessing functionality when screening for $\mathrm{MCI}$ can thus be not only part of the diagnosis but also part of early intervention planning. Suppose these two variables can help to detect cognitive deficits at their early stages. In that case, their assessment will be a method that is fast, cheap, and amenable to a large-scale application - something even more critical in LMIC. After that, more complex and expensive examinations could be requested to differentiate between etiologies and indicate further treatments.

\section{ACTIVITIES OF DAILY LIVING}

Besides having cognitive criteria, the original concept of MCI also required preserved functionality or ADL. ${ }^{6}$ 
ADL refer to tasks that are performed daily to maintain an independent life and a preserved functional capacity. It is usually divided into basic, instrumental, and advanced activities. ${ }^{45,46}$ Advanced ADL (aADL) are related to the most complex activities, such as maintaining hobbies or social life. Instrumental ADL (iADL) also have some complexity, for example, preparing meals and dealing with money, but refer to more day-to-day functional activities. Finally, basic ADL (bADL) have to do with self-care activities, such as bathing or eating. Impairment at any level can cause disability, and without the development of compensatory strategies to offset these difficulties, it can lead to dependence and decrease in the quality of life of people with dementia and their caregivers. ${ }^{47}$

At first, having deficits in ADL was the distinguishing criterion between $\mathrm{MCI}$ and dementia. ${ }^{6}$ But later evidence suggested that subtle changes already begin to occur in $\mathrm{MCI}$, especially regarding complex activities. ${ }^{44,45,48-50}$ Another study ${ }^{51}$ proposed the inclusion of "preserved basic activities of daily living (ADL)/some minimal impairment in complex instrumental function" in the diagnostic process.

Since then, the literature questioning the presence or not of difficulties in everyday abilities in $\mathrm{MCI}$ groups has grown. ${ }^{52-54}$ Today, there are still no unified guidelines to diagnose MCI. ${ }^{8}$ However, it is known that there is a progressive loss of functional capacity in the course of dementia. ${ }^{45,55,56}$ But previous studies provide conflicting results about the extent to which functional capacity is affected at each moment of the condition..$^{54,57-59}$ When cognitive decline reaches the threshold for the diagnosis of dementia, functionality is undoubtfully already compromised. $^{54}$

\section{ACTIVITIES OF DAILY LIVING ASSESSMENT}

There are many ways to measure functionality, and usually an instrument is focused on one level. Although scales are the most used tool, there are also performance-based tests and even in-home monitoring sensor technologies. ${ }^{60}$ Concerning scales, there are many options available to measure the different levels. Some examples widely used are the Lawton Instrumental Activities of Daily Living Scale developed by Lawton and Brody ${ }^{61}$ and the Pfeffer's Functional Activities Questionnaire ${ }^{62}$ to measure iADL, the Katz Activities of Daily Living ${ }^{63}$ to measure bADL, and the Advanced Activities of Daily Living scale ${ }^{64}$ to measure aADL. Using report scales is the most convenient and practical way to measure ADL, and evidence shows that they are usually correlated with cognitive scores. ${ }^{65}$
But there are also downsides to this type of assessment. There is evidence indicating that informant-and self-report often differ substantially within dementia samples. ${ }^{56,66,67}$ Self-report also does not always correspond to objective measures of cognitive functioning, ${ }^{68,69}$ and there is considerable variability in the degree to which individuals with dementia and their caregivers differ regarding their report..$^{69,70}$

One potential issue leading to the heterogeneity of results may be that individuals with dementia do not fully acknowledge the extent to which they have functional impairments. This lack of awareness about the diagnosis and its consequences, also termed anosognosia, ${ }^{71}$ is common in dementia. ${ }^{72}$ Although findings are mixed, it has been shown that people with MCI may also have limited awareness about their abilities. ${ }^{73}$ This could suggest that informant-based measures may be a better option when assessing functional abilities, but studies show that informants can underestimate abilities due to stress and caregiver burden. ${ }^{74}$

In this context, performance-based measures can provide more objective data than report scales. ${ }^{57}$ The assessment by performance-based measures requires various ADL activities to be performed in front of the examiner. ${ }^{75}$ However, direct measurements permit observation of only a small excerpt of real-world performance and are time-consuming. ${ }^{76}$ When compared to real-life monitoring, performance-based measures show different results..$^{60}$ Other downsides that can influence individual performance are the novelty of the environment and even the evaluator's presence. ${ }^{60}$

Examples of performance-based tools used to assess functional capacity in older adults are the UCSD Performance-based Skills Assessment (UPSA), whose results correlate with cognitive measures and evaluates five domains (comprehension and planning, finance, communication, transportation, and household chores), ${ }^{77}$ and the Revised Observed Test of Daily Living, which evaluates medication management, using the telephone and managing finances, but does not show a correlation with cognitive performance..$^{53}$ All types of assessment have downsides and benefits, and the evaluator must be aware of them to choose the best option for a given objective and interpret the results correctly, whereas for diagnosis purposes or intervention planning.

\section{ACTIVITIES OF DAILY LIVING PERFORMANCE AWARENESS}

One issue regarding measures that are not objective is that lack of awareness may produce an inaccurate result. Is it well known that individuals with dementia 
are usually not fully aware of their functional disabilities. ${ }^{56}$ Because of that, objective measures would be more recommended for this kind of patient. Nevertheless, ADL performance is assuredly compromised in dementia, ${ }^{78}$ so detecting functional impairment may be less of a challenge in this condition. When investigating $\mathrm{MCI}$ or another initial cognitive decline, it becomes more critical that the assessment is precise and detects subtle changes. ${ }^{57}$

Generally, studies investigating the topic use the comparison between self-report and informant-report, or self-report and performance-based measures, to determine if individuals with $\mathrm{MCI}$ are aware of their deficits. ${ }^{56,65,74,79,80}$ Both comparisons have advantages and disadvantages. While performance-based measures are more objective, they are not perfect when estimating real-life performance. ${ }^{60}$ On the other hand, comparisons to informant-report scales might be influenced by caregiver burden. ${ }^{74}$ Still, studies show its results are correlated with a patient's cognitive function and are more accurate than self-reports.$^{65}$ Findings are mixed and therefore need further investigation. This variation may be partially explained by some confounding variables, such as depression ${ }^{80}$ and cognitive level within MCI samples. ${ }^{33}$

\section{TYPES OF ERRORS IN ACTIVITIES OF DAILY LIVING PERFORMANCE}

Some definitions can help deepen the topic. In general, evidence suggests that executive functioning is the best predictor of functional capacity. ${ }^{45,58}$ Still, there is also evidence that deterioration in the ability to perform everyday tasks could be related to a general cognitive impairment. ${ }^{81}$ To understand this difference, it is useful to differentiate between commission errors (performing a step incorrectly during a task) and omission errors (not performing an action at all). Evidence shows that only the latter error is related to a deficit in general cognitive resources. ${ }^{81}$ Besides general impairment, other studies found that omission errors also seem to be linked to memory impairment. ${ }^{49,54}$ Therefore, commission and omission errors would be different components of ADL impairment and could be uncorrelated since they depend on other cognitive domains. ${ }^{81}$

Regarding completing tasks, omission errors - not performing a step - might decrease the time spent on a task but might also prevent it from being completed correctly. Instead, commission errors can increase the time spent in an activity because a step is, for example, performed more than once or less properly because of executive function deficits. ${ }^{81}$ Therefore, the task can be completed, but in more time, because some types of errors generate longer responses, either because of a longer reaction time in the step of decision-making ${ }^{82}$ or because the individual needs more time to do the same task. ${ }^{58}$ If the time spent to complete an action is part of ADL performance decline, the awareness of this decline may also be related to cognitive performance. Looking at the literature concerning awareness of deficits, one study found that anosognosia is linked to memory impairment due to a lack of updating personal information. ${ }^{83}$ The results of another study showed that individuals with lower global cognitive performance overestimated their functional performance. ${ }^{74}$

Considering the latter cognitive correlates of unawareness and that only omission errors are related to global cognitive decline and memory impairment, ${ }^{49,54,81}$ only those would be linked to overestimating performance. Commission errors, linked to executive deficits, would still be perceived and reported by individuals during assessments because this type of cognitive impairment does not seem to be related to anosognosia. ${ }^{80,84}$

\section{STATE OF THE ART AND PROPOSAL}

Diagnosis of MCI originally asked for: (1) cognitive complaint, (2) impaired cognition, and (3) preserved activities of daily living. ${ }^{22}$ As already discussed throughout this work, the last criterion has been questioned after evidence that there would already be some ADL impairment in people with $\mathrm{MCI}$ was brought to light. This concept might rely on different types of errors committed in the performance of ADL. There are commission errors (performing a step incorrectly - putting sugar twice in a recipe or baking it longer) that are related to executive functioning and hinder but do not prevent the execution of a task. ${ }^{81}$ And there are omission errors (not performing a step - not using sugar or baking at all), related to a deficit in general cognitive resources or memory and inability to complete the task.$^{49}$ Also, studies investigating cognitive correlates of anosognosia or, even more specifically, ADL deficit awareness, show that the conditions are usually related to general cognitive decline ${ }^{74}$ or memory impairment. ${ }^{83}$

If omission errors are more related to general cognitive impairment or memory deficits, ${ }^{49,54,81}$ and if the same type of impairment is usually related to unawareness, it is therefore understandable that the error might not be perceived and, thus, reported. Alternatively, a commission error, where a step is performed with some difficulty and is linked to executive deficits rather than global deficits, might occur at the beginning of functional capacity decline, where global cognition is 
still preserved. These executive deficits do not seem to prevent perception by people involved. ${ }^{80,84}$

Further investigations are needed, but the evidence presented suggests that assessing functionality with attention to commission errors could be part of routine clinical screening tests for cognitive decline. It would be much more viable than recommended expensive alternatives that are not suitable for all health care systems. ${ }^{12}$ In other words, even if recent research has shown the possibility of using biomarkers and neuroimaging to detect neurodegenerative conditions in their prodromal or advanced stages, ${ }^{85}$ those options are not viable as a screening procedure, especially in LMIC. In the latter, neuropsychological assessment is a more accessible course of action, ${ }^{12}$ even in the initial stages. ${ }^{31}$ Activities of daily living scales are already used in clinical contexts, but a closer look at errors and their awareness could suggest the onset of a pathological process in the very beginning and be a useful approach to MCI screening.

Authors' contributions. LH: conceptualization, funding acquisition, investigation, methodology, project administration, visualization, writing-original draft, and writing-review \& editing. HCF: funding acquisition, project administration, supervision, and writing-review \& editing.

\section{REFERENCES}

1. United Nations, Department of Economic and Social Affairs, Population Division. World Population Ageing 2019: Highlights (ST/ESA/SER.A/430). New York: United Nations; $20192 . \quad$ United Nations, Department of Economic and Social Affairs, Population Division. World Population Ageing 2017 - Highlights (ST/ESA/SER.A/397). New York: United Nations; 2017.

3. Brunet A, Berger SL. Epigenetics of aging and aging-related disease. J Gerontol A Biol Sci Med Sci. 2014;69(Suppl. 1):17-20. http://doi. org/10.1093/gerona/glu042

4. Alzheimer's Disease International. World Alzheimer Report 2015. The Global Impact of Dementia: an analysis of prevalence, incidence, cost and trends. 2015 [accessed on 05 July, 2020]. Available at: https://www.alz. co.uk/research/WorldAlzheimerReport2015.pdf

5. Jutkowitz E, Kane RL, Gaugler JE, MacLehose RF, Dowd B, Kuntz KM. Societal and family lifetime cost of dementia: implications for policy. J Am Geriatr Soc. 2017;65(10):2169-75. http://doi.org/10.1111/jgs.15043

6. Petersen RC. Mild cognitive impairment. Continuum (Minneap Minn). 2016;22(2 Dementia):404-18. http://doi.org/10.1212/ CON.000000000000031

7. Alzheimer's Disease International. World Alzheimer Report 2018. The state of the art of dementia research: new frontiers. London: Alzheimer's Disease International; 2018.

8. Kasper S, Bancher C, Eckert A, Förstl H, Frölich L, Hort J, et al. Management of mild cognitive impairment $(\mathrm{MCl})$ : the need for national and international guidelines. World J Biol Psychiatry. 2020;21(8):579-94. http:// doi.org/10.1080/15622975.2019.1696473

9. Steiner AB, Jacinto AF, Mayoral VF, Brucki SM, Citero VD. Mild cognitive impairment and progression to dementia of Alzheimer's disease. Rev Assoc Med Bras. 2017;63(7):651-5. http://doi.org/10.1590/18069282.63.07.651

10. Tampi RR, Tampi DJ, Chandran S, Ghori A, Durning M. Mild cognitive impairment: a comprehensive review. Heal Aging Res. 2015;4:39. http:// doi.org/10.12715/har.2015.4.39

11. Brucki S. Epidemiologia do comprometimento cognitivo leve no Brasil. Dement Neuropsychol 2013;7(4):363-6. http://dx.doi.org/10.1590/ S1980-57642013DN74000002

12. Parra MA, Baez S, Allegri R, Nitrini R, Lopera F, Slachevsky A, et al. Dementia in Latin America Assessing the present and envisioning the future. Neurology. 2018;90(5):222-31. http://doi.org/10.1212/ WNL.0000000000004897

13. Chaves ML, Camozzato AL, Godinho C, Piazenski I, Kaye J. Incidence of mild cognitive impairment and Alzheimer disease in southern Brazil. J Geriatr Psychiatry Neurol. 2009;22(3):181-7. http://doi. org/10.1177/0891988709332942

14. Ferretti C, Sarti FM, Nitrini R, Ferreira FF, Brucki SMD. An assessment of direct and indirect costs of dementia in Brazil. PLoS One. 2018;13(3):1-15. http://doi.org/10.1371/journal.pone.0193209

15. Arksey H O'Malley L. Scoping studies: towards a methodological framework. Int J Soc Res Methodol Theory Pract. 2005;8(1):19-32. http://doi. org/10.1080/1364557032000119616

16. Reisberg B, Ferris SH, de Leon MJ, Franssen ES, Kluger A, Mir P, et al. Stage-specific behavioral, cognitive, and in vivo changes in commu- nity residing subjects with age-associated memory impairment and primary degenerative dementia of the Alzheimer type. Drug Dev Res. 1988;15(2-3):101-14. http://doi.org/10.1002/ddr.430150203

17. Hughes CP, Berg L, Danziger WL, Coben LA, Martin RL. A new clinical scale for the staging of dementia. Br J Psychiatry. 1982;140:566-72. http://doi.org/10.1192/bjp.140.6.566

18. Morris JC. The clinical dementia rating (cdr): current version and scoring rules. Neurology. 1993;43(11):2412-4. http://doi.org/10.1212/wnl.43.11. 2412-a

19. Petersen RC, Smith GE, Waring SC, Ivnik RJ, Tangalos EG, Kokmen E. Mild cognitive impairment: clinical characterization and outcome. Arch Neurol. 1999;56:303-8. http://doi.org/10.1001/archneur.56.3.303

20. Clark LR, Delano-Wood L, Libon DJ, Mcdonald CR, Nation DA, Bangen $\mathrm{KJ}$, et al. Are empirically-derived subtypes of mild cognitive impairment consistent with conventional subtypes? J Int Neuropsychol Soc. 2013;19(6):635-45. http://doi.org/10.1017/S1355617713000313

21. Giau V Van, Bagyinszky E, An SS. Potential fluid biomarkers for the diagnosis of mild cognitive impairment. Int J Mol Sci. 2019;20(4149). http:// doi.org/10.3390/ijms20174149

22. Petersen RC, Doody R, Kurz A, Mohs RC, Morris JC, Rabins PV, et al. Current concepts in mild cognitive impairment. Arch Neurol. 2001;58(12):1985-92. http://doi.org/10.1001/archneur.58.12.1985

23. Breton A, Casey D, Arnaoutoglou NA. Cognitive tests for the detection of mild cognitive impairment $(\mathrm{MCl})$, the prodromal stage of dementia: meta-analysis of diagnostic accuracy studies. Int J Geriatr Psychiatry. 2019;34(2):233-42. http://doi.org/10.1002/gps.5016

24. Tsoi KK, Chan JY, Hirai HW, Wong A, Mok VC, Lam LC, et al. Recall tests are effective to detect mild cognitive impairment: a systematic review and meta-analysis of 108 diagnostic studies. J Am Med Dir Assoc. 2017;18(9):807. e17-807.e29. http://doi.org/10.1016/j.jamda.2017.05.016

25. Razak A, Ahmad NA, Chan YY, Kasim MN, Yusof M, Abdul Ghani MK, et al. Validity of screening tools for dementia and mild cognitive impairment among the elderly in primary health care: a systematic review. Public Health. 2019;169:84-92. http://doi.org/10.1016/j.puhe.2019.01.001

26. Serrano CM, Minond A, Finlay JB, Arizaga RL, Iturry M, Martinez P, et al. Validation of the Argentine version of the Montréal cognitive assessment test (MOCA) a screening tool for mild cognitive impairment and mild dementia in elderly. Dement Neuropsychol. 2020;14(2):145-52. http://doi. org/10.1590/1980-57642020dn14-020007

27. Liew TM, Feng L, Gao Q, Ng TP, Yap P. Diagnostic utility of montreal cognitive assessment in the fifth edition of diagnostic and statistical manual of mental disorders: major and mild neurocognitive disorders. J Am Med Dir Assoc. 2015;16(2):144-8. http://doi.org/10.1016/j.jamda.2014.07.021

28. Davis D, Creavin S, Yip J, Noel-Storr A, Brayne C, Cullum S. Montreal Cognitive Assessment for the diagnosis of Alzheimer's disease and other dementias. Cochrane Database Syst Rev. 2015;15(10):CD010775. https://doi.org/10.1002\%2F14651858.CD010775.pub2

29. Cesar KG, Yassuda MS, Porto FH, Brucki SM, Nitrini R. MoCA Test: normative and diagnostic accuracy data for seniors with heterogeneous educational levels in Brazil. Arq Neuro-Psiquiatr. 2019;77(11):775-81. http://doi.org/10.1590/0004-282X20190130 
30. Ortega LF, Aprahamian I, Borges MK, Cação JC, Yassuda MS. Screening for Alzheimer's disease in low-educated or illiterate older adults in brazil: A systematic review. Arq Neuro-Psiquiatr. 2019;77(4):279-88. http://doi. org/10.1590/0004-282×20190024

31. Martorelli M, Hartle L, Coutinho G, Mograbi D, Chaves D, Silberman C, et al. Diagnostic accuracy of early cognitive indicators in mild cognitive impairment. Dement Neuropsychol. 2020;14(4):358-65. http://doi.org/10.1590/1980-57642020dn14-040005

32. Barbosa EN, Faria CA, Alves HV, Lima DA, Novaes R, Fichman HC. Perfis neuropsicológicos do Comprometimento Cognitivo Leve no envelhecimento (CCL). Rev Neuropsicol Latinoam. 2015;7(2):15-23. http://doi. org/10.5579/rnl.2013.0257

33. Jak AJ, Bondi MW, Delano-Wood L, Wierenga C, Corey-Bloom J, Salmon DP, et al. Quantification of five neuropsychological approaches to defining mild cognitive impairment. Am J Geriatr Psychiatry. 2009;17(5):368-75. http://doi.org/10.1097/JGP.0b013e31819431d5

34. Godinho C, Camozzato AL, Onyszko D, Chaves ML. Estimation of the risk of conversion of mild cognitive impairment of Alzheimer type to Alzheimer's disease in a south Brazilian population-based elderly cohort: The PALA study. Int Psychogeriatr. 2012;24(4):674-81. http://doi.org/10.1017/ S1041610211002043

35. Sposito G, Neri AL, Yassuda MS. Atividades avançadas de vida diária (AAVDs) e o desempenho cognitivo em idosos residentes na comunidade: Dados do Estudo FIBRA Polo UNICAMP. Rev Bras Geriatr Gerontol. 2016;19(1):7-20. http://dx.doi.org/10.1590/1809-9823.2016.15044

36. Yassuda MS, Diniz BS, Flaks MK, Viola LF, Pereira FS, Nunes PV, et al. Neuropsychological profile of brazilian older adults with heterogeneous educational backgrounds. Arch Clin Neuropsychol. 2009;24(1):71-9. http://doi.org/10.1093/arclin/acp009

37. Brigola AG, Alexandre TD, Inouye K, Yassuda MS, Pavarini SC, Mioshi E. Limited formal education is strongly associated with lower cognitive status, functional disability and frailty status in older adults. Dement Neuropsychol. 2019;13(2):216-24. http://doi.org/10.1590/1980-57642018dn13-020011

38. Calil V, Elliott E, Borelli W, Barbosa B, Bram J, Silva F, et al. Challenges in the diagnosis of dementia: Insights from the United Kingdom-Brazil Dementia Workshop. Dement Neuropsychol. 2020;14(3):201-8. http:// doi.org/10.1590/1980-57642020dn14-030001

39. Araujo VC, Lima CM, Barbosa EN, Furtado FP, Charchat-Fichman H. Impact of age and schooling on performance on the Brief Cognitive Screening Battery: A study of elderly residents in the City of Rio de Janeiro, Brazil. Psychol Neurosci. 2018;11(3):317-28. http://doi.org/10.1037/ pne0000118

40. Dixe M, Braúna M, Camacho T, Couto F, Apóstolo J. Mild cognitive impairment in older adults. Dement Neuropsychol. 2020;14(1):28-34. http:// dx.doi.org/10.1590/1980-57642020dn14-010005

41. Chaves ML, Camozzato AL, Eizirik CL, Kaye J. Predictors of normal and successful aging among urban-dwelling elderly brazilians. Journals Gerontol - Ser B Psychol Sci Soc Sci. 2009;64(5):597-602. http://doi. org/10.1093/geronb/gbp059

42. Rinaldi J, Souza GC, Camozzato AL, Chaves ML. Sixteen-year predictors of successful aging from a southern Brazilian cohort: The PALA study. Dement Neuropsychol. 2018;12(3):228-34. http://doi.org/10.1590/ 1980-57642018dn12-030002

43. Ritchie CW, Russ TC, Banerjee S, Barber B, Boaden A, Fox NC, et al. The Edinburgh Consensus: preparing for the advent of disease-modifying therapies for Alzheimer's disease. Alzheimer's Res Ther. 2017;9(85):1-7. http://doi.org/10.1186/s13195-017-0312-4

44. Lindbergh CA, Dishman RK, Miller LS. Functional disability in mild cognitive impairment: a systematic review and meta-analysis. Neuropsychol Rev. 2016;26(2):129-59. http://doi.org/10.1007/s11065-016-9321-5

45. Cornelis E, Gorus E, Van Schelvergem N, De Vriendt P. The relationship between basic, instrumental, and advanced activities of daily living and executive functioning in geriatric patients with neurocognitive disorders. Int J Geriatr Psychiatry. 2019;34(6):889-99. http://doi.org/10.1002/ gps.5087

46. Njegovan V, Man-Son-Hing M, Mitchell SL, Molnar FJ. The hierarchy of functional loss associated with cognitive decline in older persons. J Gerontol A Biol Sci Med Sci. 2001;56(10):M638-43. http://doi.org/10.1093/ gerona/56.10.M638

47. Alzheimer's Association. 2018 Alzheimer's disease facts and figure. Alzheimers Dement. 2018;14:367-429. http://doi.org/https://doi.org/10.1016/j. jalz.2018.02.001

48. Lee MT, Jang Y, Chang WY. How do impairments in cognitive functions affect activities of daily living functions in older adults? PLoS One. 2019;14(6):1-14. http://doi.org/10.1371/journal.pone.0218112

49. Giovannetti T, Bettcher BM, Brennan L, Libon DJ, Burke M, Duey K, et al. Characterization of everyday functioning in mild cognitive impairment: A direct assessment approach. Dement Geriatr Cogn Disord. 2008;25(4):359-65. http://doi.org/10.1159/000121005
50. De Vriendt P, Gorus E, Cornelis E, Velghe A, Petrovic M, Mets T. The process of decline in advanced activities of daily living: a qualitative explorative study in mild cognitive impairment. Int Psychogeriatr. 2012;24(6):974-86. http://doi.org/10.1017/S1041610211002766

51. Winblad B, Palmer K, Kivipelto M, Jelic V, Fratiglioni L, Wahlund LO, et al. Mild cognitive impairment - beyond controversies, towards a consensus: Report of the International Working Group on Mild Cognitive Impairment. J Intern Med. 2004;256(3):240-6. http://doi.org/10.1111/j. 1365-2796.2004.01380.x

52. Pereira FS, Yassuda MS, Oliveira AM, Diniz BS, Radanovic M, Talib LL, et al. Profiles of functional deficits in mild cognitive impairment and dementia: Benefits from objective measurement. J Int Neuropsychol Soc. 2010;16(2):297-305. http://doi.org/10.1017/S1355617709991330

53. Schmitter-Edgecombe M, Parsey CM. Cognitive correlates of functional abilities in individuals with mild cognitive impairment: comparison of questionnaire, direct observation and performance-based measures Maureen. Clin Neuropsychol. 2014;25(5):726-46. http://doi.org/10.1080/1385404 6.2014.911964

54. Schmitter-Edgecombe M, Parsey CM. Assessment of functional change and cognitive correlates in the progression from healthy cognitive aging to dementia. Neuropsychology. 2014;28(6):881-93. http://doi.org/10.1037/ neu0000109

55. Slachevsky A, Forno G, Barraza P, Mioshi E, Delgado C, Lillo P, et al. Mapping the neuroanatomy of functional decline in Alzheimer's disease from basic to advanced activities of daily living. J Neurol. 2019;266(6):1310-22. http://doi.org/10.1007/s00415-019-09260-w

56. Mograbi DC, Morris RG, Fichman HC, Faria CA, Sanchez MA, Ribeiro PCC, et al. The impact of dementia, depression and awareness on activities of daily living in a sample from a middle-income country. Int J Geriatr Psychiatry. 2017;33(6):807-13. http://doi.org/10.1002/gps.4765

57. Mlinac ME, Feng MC. Assessment of activities of daily living, self-care, and independence. Arch Clin Neuropsychol. 2016;31(6):506-16. http:// doi.org/10.1093/arclin/acw049

58. Okonkwo OC, Wadley VG, Griffith HR, Ball K, Marson DC. Cognitive correlates of financial abilities in mild cognitive impairment. J Am Geriatr Soc. 2006;54(11):1745-50. http://doi.org/10.1111/j.1532-5415.2006.00916.x

59. Giebel CM, Sutcliffe C, Challis D. Hierarchical decline of the initiative and performance of complex activities of daily living in dementia. J Geriatr Psychiatry Neurol. 2017;30(2):96-103. http://doi. org/10.1177/0891988716686835

60. Lussier M, Lavoie M, Giroux S, Consel C, Guay M, Macoir J, et al. Early detection of mild cognitive impairment with in-home monitoring sensor technologies using functional measures: a systematic review. IEEE J Biomed Health Inform. 2019;23(2):838-47. http://doi.org/10.1109/ JBHI.2018.2834317

61. Lawton MP, Brody EM. Assessment of older people: Self-maintaining and instrumental activities of daily living. Gerontologist. 1969;9(3):179-86. http://doi.org/10.1093/geront/9.3 Part 1.179

62. Pfeffer RI, Kurosaki TT, Harrah $\mathrm{CH}$, Chance JM, Filos S. Measurement of functional activities in older adults in the community. J Gerontol. 1982;37(3):323-9. http://doi.org/10.1093/geronj/37.3.323

63. Katz S, Ford AB, Moskowitz RW, Jackson BA, Jaffe MW. Studies of illness in the aged the index of ADL: a standardized measure of biological and psychosocial function. JAMA. 1963;185(12):914-9. http://doi. org/10.1001/jama.1963.03060120024016

64. Reuben DB, Laliberte L, Hiris J, Mor V. A hierarchical exercise scale to measure function at the advanced Activities of Daily Living (AADL) level. J Am Geriatr Soc. 1990;38(8):855-61. http://doi.org/10.1111/j.1532-5415.1990.tb05699.x

65. Miller S, Brown C, Mitchell M, Williamson G. Activities of daily living are associated with older adult cognitive status: Caregiver versus self-reports. J Appl Gerontol. 2013;32(1):3-30. http://doi. org/10.1177/0733464811405495

66. DeBettignies BH, Mahurin RK, Pirozzolo FJ. Insight for impairment in independent living skills in Alzheimer's disease and multi-infarct dementia. J Clin Exp Neuropsychol. 1990;12(2):355-63. http://doi. org/10.1080/01688639008400980

67. Clare L, Nelis SM, Martyr A, Roberts J, Whitaker CJ, Markova IS, et al. The influence of psychological, social and contextual factors on the expression and measurement of awareness in early-stage dementia: Testing a biopsychosocial model. Int J Geriatr Psychiatry. 2012;27(2):167-77. http://doi.org/10.1002/gps.2705

68. Michon A, Deweer B, Pillon B, Agid Y, Dubois B. Relation of anosognosia to frontal lobe dysfunction in Alzheimer's disease. J Neurol Neurosurg Psychiatry. 1994;57(7):805-9. http://doi.org/10.1136/jnnp.57.7.805

69. Tierney MC, Szalai JP, Snow G, Fisher RH. The prediction of Alzheimer disease: the role of patient and informant perceptions of cognitive deficits. Arch Neurol. 1996;53(5):423. http://doi.org/10.1001/archneur.1996.00550050053023 
70. Reed BR, Jagust WJ, Coulter L. Anosognosia in Alzheimer's disease: Relationships to depression, cognitive function, and cerebral perfusion. J Clin Exp Neuropsychol. 1993;15(2):231-44. http://doi. org/10.1080/01688639308402560

71. Mograbi DC, Morris R. Anosognosia. Cortex. 2018;103:385-6. http://doi. org/10.1016/j.cortex.2018.04.001

72. Mograbi DC, Ferri CP, Sosa AL, Stewart R, Laks J, Brown R, et al. Unawareness of memory impairment in dementia: A population-based study. Int Psychogeriatr. 2012;24(6):931-9. http://doi.org/10.1017/ S1041610211002730

73. Tabert MH, Albert SM, Borukhova-Milov L, Camacho Y, Pelton G, Liu $X$, et al. Functional deficits in patients with mild cognitive impairment: prediction of Alzheimer冈s disease. Neurology. 2002;58(5):758-64. http:// doi.org/10.1212/wnl.58.5.758

74. Okonkwo OC, Wadley VG, Griffith HR, Belue K, Lanza S, Zamrini EY, et al. Awareness of deficits in financial abilities in patients with mild cognitive impairment: going beyond self-informant discrepancy. Am J Geriatr Psychiatry. 2008;16(8):650-9. http://doi.org/10.1097/JGP.0b013e31817e8a9d. AWARENESS

75. Schmitter-Edgecombe M, Woo E, Greeley DR. Characterizing multiple memory deficits and their relation to everyday functioning in individuals with mild cognitive impairment. Neuropsychology. 2009;23(2):168-77. http://doi.org/10.1037/a0014186

76. Jekel K, Damian M, Wattmo C, Hausner L, Bullock R, Connelly PJ, et al. Mild cognitive impairment and deficits in instrumental activities of daily living: A systematic review. Alzheimers Res Ther. 2015;7(17). http://doi. org/10.1186/s13195-015-0099-0

77. Becattini-Oliveira AC, Portela Câmara LC, Dutra DF, Sigrist AD, Charchat-Fichman $\mathrm{H}$. Performance-based instrument to assess functional capacity in community-dwelling older adults. Dement Neuropsychol. 2019;13(4):386-93. http://doi.org/10.1590/1980-57642018dn13-040004

78. American Psychiatric Association. Diagnostic and statistical manual of mental disorders. 5. ed. Arlington: APA; 2013.

79. Farias ST, Mungas D, Jagust W. Degree of discrepancy between self and other-reported everyday functioning by cognitive status: dementia, mild cognitive impairment, and healthy elders. Int J Geriatr Psychiatry. 2005;20(9):827-34. https://doi.org/10.1002/gps.1367

80. Suchy Y, Kraybill ML, Franchow E. Instrumental activities of daily living among community-dwelling older adults: Discrepancies between self-report and performance are mediated by cognitive reserve. J Clin Exp Neuropsychol. 2011;33(1):92-100. http://doi.org/10.1080/13803395.2010.493148

81. Giovannetti T, Bettcher BM, Brennan L, Libon DJ, Kessler RK, Duey K. Coffee with jelly or unbuttered toast: commissions and omissions are dissociable aspects of everyday action impairment in Alzheimer's disease. Neuropsychology. 2008;22(2):235-45. http://doi.org/10.1037/08944105.22.2.235

82. Andriuta D, Diouf M, Roussel M, Godefroy $O$. Is reaction time slowing an early sign of alzheimer's disease? a meta-analysis. Dement Geriatr Cogn Disord. 2019;47(4-6):281-8. http://doi.org/10.1159/000500348

83. Mograbi DC, Brown RG, Morris RG. Anosognosia in Alzheimer's disease the petrified self. Conscious Cogn. Academic Press; 2009;18(4):989-1003. http://doi.org/10.1016/J.CONCOG.2009.07.005

84. Starkstein SE, Sabe L, Cuerva AG, Kuzis G, Leiguarda R. Anosognosia and procedural learning in Alzheimer's disease. Neuropsychiatry Neuropsychol Behav Neurol. 1997 Apr;10(2):96-101.

85. Petersen RC. How early can we diagnose Alzheimer disease (and is it sufficient)? Neurology. 2018;91(9):395-402. http://doi.org/10.1212/ WNL.0000000000006088 